Int. J. Electrochem. Sci., 11 (2016) $8439-8446$

International Journal of

ELECTROCHEMICAL

SCIENCE

www.electrochemsci.org

\title{
ZnO Nanorods Grown Directly on Copper Foil Substrate as a Binder-Free Anode for High Performance Lithium-Ion Batteries
}

\author{
Lanyan Huang ${ }^{1,5}$, Xin Wang ${ }^{1, *}$, Fuxing Yin ${ }^{2,3}$, Yongguang Zhang ${ }^{2,3, *}$, Jinwei Gao ${ }^{5}$, Junming Liu ${ }^{5}$, \\ Guofu Zhoul and Zhumabay Bakenov ${ }^{2,4}$ \\ ${ }^{1}$ Institute of Electronic Paper Displays, South China Academy of Advanced Optoelectronics, South \\ China Normal University, Guangzhou, Guangdong Province, China. \\ ${ }^{2}$ Synergy Innovation Institute of GDUT, Heyuan, Guangdong Province, China \\ ${ }^{3}$ Research Institute for Energy Equipment Materials, Tianjin key laboratory of laminating fabrication \\ and interface control technology for advanced materials, Hebei University of Technology, Tianjin \\ 300130, China \\ ${ }^{4}$ Institute of Batteries LLC, Center of Energy and Advanced Materials Science, PI National Laboratory \\ Astana, School of Engineering, Nazarbayev University, 53 Kabanbay Batyr Avenue, Astana 010000, \\ Kazakhstan \\ ${ }^{5}$ Institute of Advanced Materials, South China Academy of Advanced Optoelectronics, South China \\ Normal University, Guangzhou, Guangdong Province, China. \\ *E-mail: yongguangzhang@hebut.edu.cn; wangxin@scnu.edu.cn
}

doi: $10.20964 / 2016.10 .60$

Received: 4 July 2016 / Accepted: 29 August 2016 / Published: 6 September 2016

$\mathrm{ZnO}$ nanorods directly grown on copper foil substrate were obtained via hydrothermal method without using templates. Structure and morphology of the as-prepared $\mathrm{ZnO}$ nanorods were characterized by $\mathrm{X}$ ray diffraction, scanning electron microscopy and high-resolution transmission electron microscopy. The $\mathrm{ZnO}$ nanorods on copper foil ( $\mathrm{ZnO} @ \mathrm{CF}$ ) exhibited remarkably enhanced performance as anode for lithium batteries with the initial discharge capacity of $1236 \mathrm{mAh} \mathrm{g}^{-1}$ and a capacity of $402 \mathrm{mAh} \mathrm{g}^{-1}$ retained over 100 cycles at a current density of $200 \mathrm{~mA} \mathrm{~g}^{-1}$. The $\mathrm{ZnO} @ \mathrm{CF}$ anode demonstrated an excellent rate capability, delivering a reversible capacity of $390 \mathrm{mAh} \mathrm{g}^{-1}$ at $1500 \mathrm{~mA} \mathrm{~g}^{-1}$. This superior performance of the $\mathrm{ZnO} @ \mathrm{CF}$ anode is believed to be due to the unique structure of this binder-free anode, favoring mass and charge transfer at its interface with the electrolyte, effectively reducing the Li-ions diffusion paths and providing conditions to accommodate the anode volume variations upon charge-discharge cycling.

Keywords: Lithium ion battery, Anode, $\mathrm{ZnO}$ nanorods, Binder-free

$\underline{\text { FULL TEXT }}$ 
(C) 2016 The Authors. Published by ESG (www.electrochemsci.org). This article is an open access article distributed under the terms and conditions of the Creative Commons Attribution license (http://creativecommons.org/licenses/by/4.0/). 